\title{
The Importance of Diffusivity and Partitioning Behavior of Solid Solution Strengthening Elements for the High Temperature Creep Strength of Ni-Base Superalloys
}

\author{
S. GIESE, A. BEZOLD, M. PRÖBSTLE, A. HECKL, S. NEUMEIER, and M. GÖKEN
}

\begin{abstract}
The creep resistance of single-crystalline Ni-base superalloys at elevated temperatures depends among others on solid solution strengthening of the $\gamma$-matrix. To study the influence of various solid solution strengtheners on the mechanical properties, a series of Ni-base superalloys with the same content of different alloying elements (Ir, Mo, Re, Rh, Ru, W) or element combinations (MoW, ReMo, ReW) was investigated. Nanoindentation measurements were performed to correlate the partitioning behavior of the solid solution strengtheners with the hardness of the individual phases. The lowest $\gamma^{\prime} / \gamma$-hardness ratio was observed for the Re-containing alloy with the strongest partitioning of Re to the $\gamma$-matrix. As a result of the creep experiments in the high-temperature/low-stress regime $\left(1373 \mathrm{~K}\left(1100{ }^{\circ} \mathrm{C}\right) / 140 \mathrm{MPa}\right)$, it can be concluded that solid solution hardening in the $\gamma$-phase plays an essential role. The stronger the partitioning to the $\gamma$-phase and the lower the interdiffusion coefficient of the alloying element, the better the creep resistance. Therefore, the best creep behavior is found for alloys containing high contents of slow-diffusing elements that partition preferably to the $\gamma$-phase, particularly Re followed by W and Mo.
\end{abstract}

https://doi.org/10.1007/s11661-020-06028-0

(C) The Author(s) 2020

\section{INTRODUCTION}

MODERN nickel-base superalloys contain many alloying elements to improve the mechanical properties and to increase the operating temperatures for higher efficiency. Their microstructure consists of $\gamma^{\prime}$-precipitates $\left(\mathrm{L}_{2}\right.$-structure), which are coherently embedded in a soft $\gamma$-matrix (A1-structure). The creep behavior of superalloys is a key factor regarding the lifetime of a turbine blade. In addition to the microstructural characteristics like the $\gamma^{\prime}$-volume fraction, $\gamma^{\prime}$-size and $\gamma^{\prime}$-morphology, the mechanical properties mostly depend on the solid solution hardening of the $\gamma$-phase, especially in the high-temperature/low-stress regime (e.g., $1373 \mathrm{~K}$

S. GIESE, A. BEZOLD, M. PRÖBSTLE, S. NEUMEIER, and M. GÖKEN are with the Friedrich-Alexander-Universität ErlangenNürnberg (FAU), Department of Materials Science \& Engineering, Institute I: General Materials Properties, Martensstr. 5, 91058 Erlangen, Germany. Contact e-mail: andreas.bezold@fau.de A. HECKL is with the Friedrich-Alexander-Universität ErlangenNürnberg (FAU), Department of Materials Science \& Engineering, Institute II: Materials Science and Engineering for Metals (WTM), Martensstr. 5, 91058 Erlangen, Germany, and now also with the Schaeffler Technologies AG \& Co. KG, Industriestraße 1-3, 91074 Herzogenaurach, Germany.

Manuscript submitted June 19, 2020. Accepted September 10, 2020.

Article published online October 7, 2020 $\left.\left(1100{ }^{\circ} \mathrm{C}\right) / 140 \mathrm{MPa}\right) .{ }^{[1-4]}$ At small strains deformation occurs mainly in the $\gamma$-channels, since the required stress for cutting the $\gamma^{\prime}$-phase by dislocations is not high enough. ${ }^{[5,6]}$ To strengthen the $\gamma$-phase, the alloying elements must preferentially partition to the $\gamma$-matrix and should have a low interdiffusion coefficient in the $\mathrm{Ni}$ solid solution. Alloying elements can be divided into two groups depending on their partitioning coefficient $k_{i}^{\gamma^{\prime} / \gamma}$, which is given as follows:

$$
k_{i}^{\gamma^{\prime} / \gamma}=\frac{c_{i}^{\gamma^{\prime}}}{c_{i}^{\gamma}}
$$

where $c_{i}^{\gamma^{\prime}}$ and $c_{i}^{\gamma}$ represent the atomic fractions $c$ of an element $i$ in the $\gamma^{\prime}$ - and $\gamma$-phase, respectively. Elements like $\mathrm{Co}, \mathrm{Cr}, \mathrm{Ru}, \mathrm{Re}, \mathrm{Mo}$ and $\mathrm{W}$ are enriched in the $\gamma$-phase $(k<1)$ and stabilize it because of the similar size of their atomic radii compared to $\mathrm{Ni}$, whereas the $\gamma^{\prime}$-phase is stabilized by Al, Ta and Ti $(k>1) .{ }^{[7,8]}$

To correlate the concentration and diffusivity of solid solution strengtheners in the $\gamma$-phase with the creep properties at high temperatures, Zhu et al. introduced a model for creep deformation that includes the calculation of the effective diffusion coefficient. ${ }^{[9]}$ This approach was also used in the study by Proebstle et al. to explain the beneficial effect of the optimized partitioning behavior of $\mathrm{W}$ on the creep strength of a series of 
Ni-base superalloys. ${ }^{[10]}$ Besides the element $\mathrm{W}$, a variety of different other alloying elements was added during the last 60 years of alloy development of Ni-base superalloys to study their impact on the creep strength. It was found that W, Mo and especially Re can act as effective solid solution strengtheners and therefore have a beneficial effect on the mechanical properties of turbine blades under operating conditions. ${ }^{11,12]}$ The importance of the addition of Re becomes apparent with the classification in Ni-base superalloys as the first, second and third generation, according to the amount of Re. ${ }^{[13]}$ The low diffusion coefficient as well as the strong tendency to be enriched in the $\gamma$-phase seem to be responsible for the beneficial effect of Re additions. ${ }^{[14]}$ Additionally, the segregation of Re to dislocations in the $\gamma^{\prime}$-precipitates reduces their glide velocity and thus improves the creep performance. ${ }^{[15]}$ To replace the rare element Re, the potent solid solution strengthener W can also be used. Rettig et al. could show that W-rich alloys can achieve similar creep properties to Re-containing alloys. ${ }^{[16]}$ However, the potential of $\mathrm{W}$ is limited because of its lower enrichment in the $\gamma$-matrix. ${ }^{[17]}$ Pröbstle et al. revealed that the partitioning behavior of $\mathrm{W}$ can be positively influenced by increasing the amount of $\mathrm{Ti}$, which leads to a stronger enrichment of $\mathrm{W}$ in the $\gamma$-matrix. ${ }^{[10]}$ Similarly, Amouyal et al. showed by atom probe tomography (APT) that Ta acts in the same way and forces $\mathrm{W}$ to partition more strongly in the $\gamma$-phase. ${ }^{[18]}$ The reason for this is that both elements compete for the $\mathrm{Al}$ sites and push $\mathrm{W}$ to the $\gamma$-phase. The advantage of slow-diffusing elements like Re and $\mathrm{W}$ is that they retard dislocation climb at the $\gamma / \gamma^{\prime}$-interfaces. ${ }^{[9]}$ Solid solution strengthening by slow-diffusing elements may also introduce back stresses, additionally hindering dislocation climb processes at elevated temperatures improving the creep strength. ${ }^{[19,20]}$ Besides Re and W, Ir, $\mathrm{Ru}$ and $\mathrm{Rh}$ are also relatively slow-diffusing elements. ${ }^{[21,22]} \mathrm{Ru}$ is primarily added, because the addition of $3 \mathrm{wt}$ pct Ru can effectively suppress the formation of detrimental TCP phases. ${ }^{[23,24]} \mathrm{Ru}$ leads to a decrease of the supersaturation of the $\gamma$-phase and increases the required elastic strain energy for the nucleation of TCP phases. ${ }^{[25]}$ Ir and $\mathrm{Rh}$ also exhibit low diffusion coefficients, but distribute almost uniformly in the $\gamma$ - and $\gamma^{\prime}$-phase. ${ }^{[26-28]}$

In summary, it can be concluded that there is consensus about the influence of most of the typical alloying elements; however, the influence of the extremely rare elements Ir and Rh on the creep properties of superalloys is less investigated so far and often a direct comparison of the potential of different solid solution strengtheners is not possible. Either different concentrations of solutes are added or several solid solution strengtheners are alloyed simultaneously. To evaluate the role of a variety of potential solid solution strengtheners on the creep properties in the high-temperature regime systematically, a series of Ni-base superalloys with the same base composition and the same content of solid solution strengtheners was investigated. The elements Ir, Mo, Re, Rh, Ru and $\mathrm{W}$ of the fifth and sixth period of the transition metals were chosen, because they are the most slowly diffusing elements. The different factors contributing to the creep behavior such as the $\gamma^{\prime}$-volume fraction, $\gamma^{\prime}$-size and $\gamma^{\prime}$-morphology of the precipitates as well as solid solution strengthening of the $\gamma$-phase were considered, with the focus on the partitioning behavior of each element and the resulting effective diffusion coefficient. The aim was to understand the alloys' creep behavior in the high-temperature regime and to rank the slowly diffusing elements Ir, $\mathrm{Mo}, \mathrm{Re}, \mathrm{Rh}, \mathrm{Ru}$ and $\mathrm{W}$ regarding their potential for solid solution strengthening.

\section{MATERIAL AND EXPERIMENTAL METHODS}

\section{A. Alloy Composition and Manufacturing}

The influence of individual alloying elements as well as three combinations of the most common solid solution strengtheners on the microstructure and mechanical properties was studied in this work. The base composition is derived from the base alloy of the Astra1 series by Heckl et al. without the addition of Mo and $\mathrm{W} \cdot{ }^{[29,30]}$ The alloys cast for this work are called Astra2 alloys and their base composition consists of $\mathrm{Ni}$, $\mathrm{Al}, \mathrm{Co}, \mathrm{Cr}$ and $\mathrm{Ta}$. The derived Astra2 alloys contain additionally 3.6 at. pct of one alloying element such as $\mathrm{Ir}, \mathrm{Mo}, \mathrm{Re}, \mathrm{Rh}, \mathrm{Ru}$ and $\mathrm{W}$ to investigate the influence of each element separately. The alloys Astra2-ReW, -ReMo and -MoW contain 3.6 at. pct Re plus W, Re plus Mo or Mo plus W, as shown in Table I.

Single crystalline cylindrical bars of each alloy were produced by a Bridgman vacuum casting unit. Further details regarding the casting process were published earlier by Heckl et al. ${ }^{[29]}$ The alloys were solution heat treated at $1573 \mathrm{~K}\left(1300^{\circ} \mathrm{C}\right)$ for 12 hours in a vertical furnace (type RoF 7/75 Heraeus, Hanau, Germany) and subsequently water quenched to dissolve the $\gamma^{\prime}$-phase and intermetallic phases in the interdendritic regions and to homogenize the material. To achieve a similar $\gamma^{\prime}$-size before creep testing, preliminary heating tests were performed. Afterwards, solution annealing and age hardening were done in two steps at $1373 \mathrm{~K}$ to $1413 \mathrm{~K}$ $\left(1100{ }^{\circ} \mathrm{C}\right.$ to $\left.1140{ }^{\circ} \mathrm{C}\right)$ for 1.5 to 5 hours and $1143 \mathrm{~K}$ $\left(870^{\circ} \mathrm{C}\right)$ for 24 hours under argon atmosphere in the same furnace (Tube furnace R140/800/14, Nabertherm, Linienthal, Germany); see Table II.

The $\gamma^{\prime} / \gamma$-partitioning behavior of the elements was analyzed by EDS measurements using an INCA PentaFET-x3 detector from Oxford Instruments. Coarsened microstructures with larger $\gamma^{\prime}$-precipitates and broader $\gamma$-channel widths were generated by a long-term heat treatment of 1000 hours at $1373 \mathrm{~K}\left(1100{ }^{\circ} \mathrm{C}\right)$ under vacuum. Water quenching was done afterwards.

\section{B. Microstructural Characterization}

After full heat treatment, the samples were ground and mechanically polished up to $1 \mu \mathrm{m}$ with a diamond suspension for microstructural characterization. The final polishing step was done by OPS polishing $(0.025 \mu \mathrm{m})$ from Struers (Struers $\mathrm{GmbH}$, Ottensoos, 
Table I. Nominal Composition of Astra2 Alloys in At. Pet.

\begin{tabular}{|c|c|c|c|c|c|c|c|c|c|c|c|}
\hline Astra2- & $\mathrm{Ni}$ & $\mathrm{Al}$ & $\mathrm{Co}$ & $\mathrm{Cr}$ & $\mathrm{Ta}$ & Ir & Mo & $\mathrm{Re}$ & $\mathrm{Rh}$ & $\mathrm{Ru}$ & W \\
\hline Base & 69.30 & 13.50 & 9.00 & 6.00 & 2.20 & & & & & & \\
\hline $\mathrm{Ir}$ & 65.70 & 13.50 & 9.00 & 6.00 & 2.20 & 3.60 & & & & & \\
\hline Mo & 65.70 & 13.50 & 9.00 & 6.00 & 2.20 & & 3.60 & & & & \\
\hline $\mathrm{Re}$ & 65.70 & 13.50 & 9.00 & 6.00 & 2.20 & & & 3.60 & & & \\
\hline $\mathrm{Rh}$ & 65.70 & 13.50 & 9.00 & 6.00 & 2.20 & & & & 3.60 & & \\
\hline $\mathrm{Ru}$ & 65.70 & 13.50 & 9.00 & 6.00 & 2.20 & & & & & 3.60 & \\
\hline W & 65.70 & 13.50 & 9.00 & 6.00 & 2.20 & & & & & & 3.60 \\
\hline MoW & 65.70 & 13.50 & 9.00 & 6.00 & 2.20 & & 2.60 & & & & 1.00 \\
\hline ReMo & 65.70 & 13.50 & 9.00 & 6.00 & 2.20 & & 2.60 & 1.00 & & & \\
\hline ReW & 65.70 & 13.50 & 9.00 & 6.00 & 2.20 & & & 1.00 & & & 2.60 \\
\hline
\end{tabular}

Table II. Standard Heat Treatments for Astra2 Alloys

\begin{tabular}{|c|c|c|c|c|}
\hline \multirow{2}{*}{$\frac{\text { Astra2- }}{\text { Base }}$} & \multicolumn{2}{|c|}{$\begin{array}{c}\text { 1. Heat treatment } \\
\text { Temperature/K Duration/h }\end{array}$} & \multicolumn{2}{|c|}{$\begin{array}{l}\text { 2. Heat treatment } \\
\text { Temperature/K Duration/h }\end{array}$} \\
\hline & 1373 & 1.5 & 1143 & 24 \\
\hline Ir & 1373 & 2.5 & 1143 & 24 \\
\hline Mo & 1373 & 2.5 & 1143 & 24 \\
\hline $\mathrm{W}$ & 1373 & 2.5 & 1143 & 24 \\
\hline $\mathrm{Rh}$ & 1373 & 3 & 1143 & 24 \\
\hline $\mathrm{Ru}$ & 1373 & 4 & 1143 & 24 \\
\hline $\mathrm{Re}$ & 1413 & 5 & 1143 & 24 \\
\hline MoW & 1373 & 2.5 & 1143 & 24 \\
\hline ReMo & 1413 & 3 & 1143 & 24 \\
\hline ReW & 1413 & 3 & 1143 & 24 \\
\hline
\end{tabular}

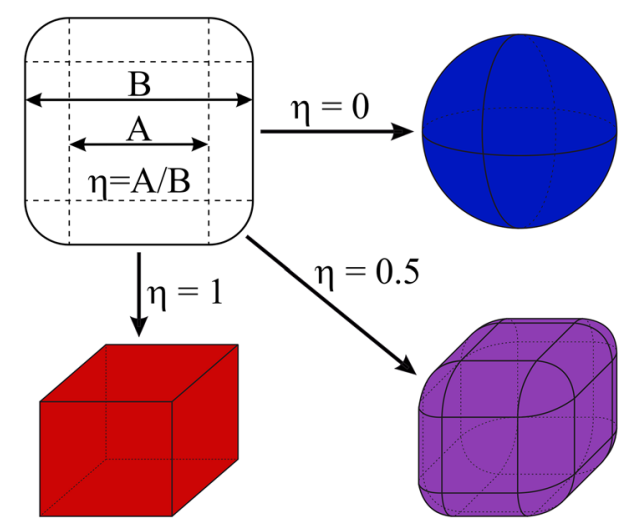

Fig. 1-Definition of the morphology factor $\eta$ and the resulting $\gamma^{\prime}$-precipitate shapes equal to $0,0.5$ and 1 according to MacSleyne et al. ${ }^{[32]}$ The schematic in the upper left is adapted from Ref. 32.

Germany). Microstructural analysis was carried out with a Zeiss Crossbeam 540 XB (Zeiss GmbH, Oberkochen, Germany) using back-scattered electron imaging (BSE) and an accelerating voltage of $20 \mathrm{kV}$. The $\gamma^{\prime}$-morphology, $\gamma^{\prime}$-volume fraction, $\gamma^{\prime}$-size and $\gamma$-channel width of the Astra2 alloys were determined using binarized SEM images containing at least 200 precipitates with ImageJ software. ${ }^{[31]}$ Therefore, the morphology factor $\eta$ was determined, which is defined as the ratio of two shape parameters A and B as shown in Figure 1. Perfectly spherical precipitates have a $\eta$ of 0 , whereas idealized cubic precipitates have a $\eta$ of 1 . According to MacSleyne et al., the morphology factor $\eta$ correlates with the absolute moment invariant $\omega_{2}$ as follows: ${ }^{[32]}$

$$
\omega_{2}=\frac{144\left(\pi(\eta-1)^{2}-4 \eta(\eta-2)\right)^{4}}{\left(3 \pi(\eta-1)^{2}\left(1-2 \eta+5 \eta^{2}\right)-16 \eta\left(3 \eta^{3}-7 \eta^{2}+6 \eta-3\right)\right)^{2}} .
$$

Following the approach of MacSleyne et al., the absolute 2D moment invariant $\omega_{2}$, which is invariant for similarity and affine transformations, was measured for each precipitate and subsequently converted to the morphology factor $\eta .^{[32]}$ Afterwards, the average morphology factors $\eta_{\text {sum }}$ for the Astra2 alloys were calculated and plotted with the 5 pct standard error in Figure 3(a), similar to Van Sluytman and Pollock. ${ }^{[33]}$

The average morphology factor $\eta_{\text {sum }}$ was also used to determine the volume fraction of ordered $\gamma^{\prime}$-precipitates with rounded corners. Bürgel et al. have shown that the measured area fraction of regularly ordered, cubic $\gamma^{\prime}$-precipitates in the [001] direction is not equal to the volume fraction. ${ }^{[7]}$ Consequently, they derived an equation that converts the easily measured $\gamma^{\prime}$-area fraction into a $\gamma^{\prime}$-volume fraction. However, the assumption of perfect cuboidal precipitates is not fulfilled in realistic $\gamma /$ 
$\gamma^{\prime}$-microstructures. Therefore, the average morphology factor $\eta_{\text {sum }}$ was incorporated in the approach of Bürgel et $a{ }^{\left[{ }^{[7]}\right.}$ The following modified equation for converting the $\gamma^{\prime}$-area fraction $f_{\mathrm{A}}$ into a $\gamma^{\prime}$-volume fraction $f_{\mathrm{V}}$ was derived, which facilitates a more precise determination of the $\gamma^{\prime}$-volume fraction:

$$
\begin{aligned}
& f_{v}=\frac{Q^{3}\left(3 \eta^{2}-2 \eta^{3}+\frac{3 \pi}{4} \eta(1-\eta)^{2}+\frac{\pi}{6}(1-\eta)^{3}\right)}{Q^{3}+3 Q^{2}+3 Q+1} \\
& \text { with } Q=\frac{f_{\mathrm{A}}+\sqrt{f_{\mathrm{A}}\left(2 \eta-\eta^{2}+\frac{\pi}{4}-\frac{\eta \pi}{2}+\frac{\eta^{2} \pi}{4}\right)}}{-f_{\mathrm{A}}+2 \eta-\eta^{2}+\frac{\pi}{4}-\frac{\eta \pi}{2}+\frac{\eta^{2} \pi}{4}}=\frac{B}{w},
\end{aligned}
$$

where $Q$ is defined as the ratio of the length parameter $B$ and the channel width $w$. The reader is referred to the Appendix for the mathematical derivation.

The cubic volume equivalent $\gamma^{\prime}$-edge length was calculated for each individual precipitate as a function of the respective area and morphology factor assuming an approximately equiaxed shape in three dimensions. Using the average $\gamma^{\prime}$-size and the $Q$-factor, as defined above, the average $\gamma$-channel width was determined. For more details on the calculations of the $\gamma^{\prime}$-volume fraction, $\gamma^{\prime}$-size and $\gamma$-channel width, the reader is referred to Appendix.

\section{Mechanical Testing}

The hardness of the $\gamma$-matrix and the $\gamma^{\prime}$-precipitates of the standard heat-treated conditions was determined by nanoindentation at room temperature with a TriboScope Hysitron from Bruker (Bruker, MA) mounted on a Veeco Instruments Multimode AFM (NI-AFM) as used in a former study by Neumeier et al. ${ }^{[34]}$ A diamond tip with a cube corner geometry was used for indentation. According to the Oliver-Pharr-method, the hardness of the $\gamma$-matrix and the $\gamma^{\prime}$-precipitates were calculated from the unloading part of the load displacement curves. ${ }^{[35]}$ At least 15 indents in each phase per alloy were evaluated with a maximum force of $250 \mu \mathrm{N}$ and a maximum indentation depth of about $45 \mathrm{~nm}$.

Constant creep tests under compression were performed on plan-parallel cylindrical specimens with a height of $7.5 \mathrm{~mm}$ and a diameter of $5 \mathrm{~mm}$ up to 4 pct plastic strain at $1373 \mathrm{~K}\left(1100^{\circ} \mathrm{C}\right)$ and $140 \mathrm{MPa}$. Stress and temperature were kept constant during testing. Two type $\mathrm{S}$ thermocouples were in direct contact with the samples controlling the temperature during testing. Sample deformation was measured by a laser extensometer (Fiedler Optoelektronik GmbH, Lützen, Germany).

\section{RESULTS}

\section{A. Microstructure}

The microstructure of all Astra2 alloys after full heat treatment is shown in Figure 2. All alloys show a two-phase $\gamma / \gamma^{\prime}$-microstructure with no remaining
Fig. 2-SEM micrographs using a back-scattered electron detector (BSE), (a) Astra2-Base, (b) Astra2-Ir, (c) Astra2-Mo, (d) Astra2-W, (e) Astra2-Rh, (f) Astra2-Ru, ( $g$ ) Astra2-Re, (h) Astra2-MoW, (i) Astra2-ReMo and ( $j$ ) Astra2-ReW after full heat treatment.

eutectics or TCP phases, except for the Astra-Rh alloy, where third phases are visible. EDS measurements indicate that this phase is $\beta$ - $(\mathrm{Ni}, \mathrm{Rh}) \mathrm{Al}$, which is thermally stable over a wide range in the Al-Ni-Rh ternary system according to investigations of Przepiórzyński et $a l .{ }^{[36]}$ These results are in good agreement with studies from Murakami et al. who stated that elements like Rh, $\mathrm{Ru}$ and $\mathrm{Ir}$ form $\mathrm{B} 2$-phases with $\mathrm{Al}^{[26]}$ and that the microstructure will change from $\gamma+\gamma^{\prime}$ to $\beta+\gamma+\gamma^{\prime}$, if a critical $\mathrm{Rh}$ content is present. In addition to the larger primary $\gamma^{\prime}$-precipitates, also smaller secondary $\gamma^{\prime}$-precipitates are found in the $\gamma$-matrix of the Astra 2 alloys containing Ir, Ru, Re and especially $\mathrm{Rh}$.

Figure 3 indicates that the morphology factor of the Astra 2 series varies quite strongly with different alloying elements. The Astra2 base alloy has the highest morphology factor $\eta$ of about 0.61 with a nearly cuboidal shape (Figure 3(a)). A change to a more spherical shape and therefore lower lattice misfits can be observed in all alloys with additional alloying elements and is most pronounced in the Astra2-Re alloy with the lowest morphology factor $\eta$ of about 0.22 . For spherical precipitates in an unordered arrangement, the measured area fraction and the actual volume fraction are equal, which is the case for the Astra2-Re and Astra2-Ru alloys. The morphology factor $\eta$ of 0.4 seems to represent the dividing line between periodically aligned and randomly distributed $\gamma^{\prime}$-precipitates for the investigated alloys, although the transition is smooth and not sharp.

The $\gamma^{\prime}$-volume fraction of the Astra2 alloys after age hardening is in the range of $59 \pm 4$ pct, except for the Irand Rh-containing alloys; see Figure 3(b). In these alloys the $\gamma^{\prime}$-volume fraction is significantly lower because the $\mathrm{Rh}$-containing alloy additionally contains the $\beta$-(Ni,Rh)-Al-phase and the very small secondary $\gamma^{\prime}$-precipitates in both alloys were not taken into account. These secondary $\gamma^{\prime}$-precipitates are formed at the second heat treatment step at $1143 \mathrm{~K}\left(870{ }^{\circ} \mathrm{C}\right)$ and dissolve again during creep at $1373 \mathrm{~K}\left(1100{ }^{\circ} \mathrm{C}\right)$ and therefore are not considered to beneficially contribute to the creep properties at elevated temperatures.

The adjusted treatment resulted in a similar mean equivalent cubic volume $\gamma^{\prime}$-edge length (see Appendix A.2), henceforth referred to as $\gamma^{\prime}$-size, of $454 \pm 33 \mathrm{~nm}$ (Figure 3(c)). A slightly larger $\gamma^{\prime}$-size of $528 \pm 116 \mathrm{~nm}$ and one of the highest $\gamma^{\prime}$-volume fraction was observed for Astra2-W. In contrast to that the $\gamma^{\prime}$-precipitates of the Astra2-ReMo alloy possess a smaller mean $\gamma^{\prime}$-size of $372 \pm 56 \mathrm{~nm}$. The comparatively small precipitate size of the Astra2-Ir with $295 \pm 64 \mathrm{~nm}$ might result from the irregular shape of the Ir-containing precipitates; see Figure 2(b). In correlation with the $\gamma^{\prime}$-volume fraction, the $\gamma$-channel width follows an opposite trend according to the equation explained in detail in Appendix. Therefore, the $\gamma$-channel widths of all Astra2 alloys are 

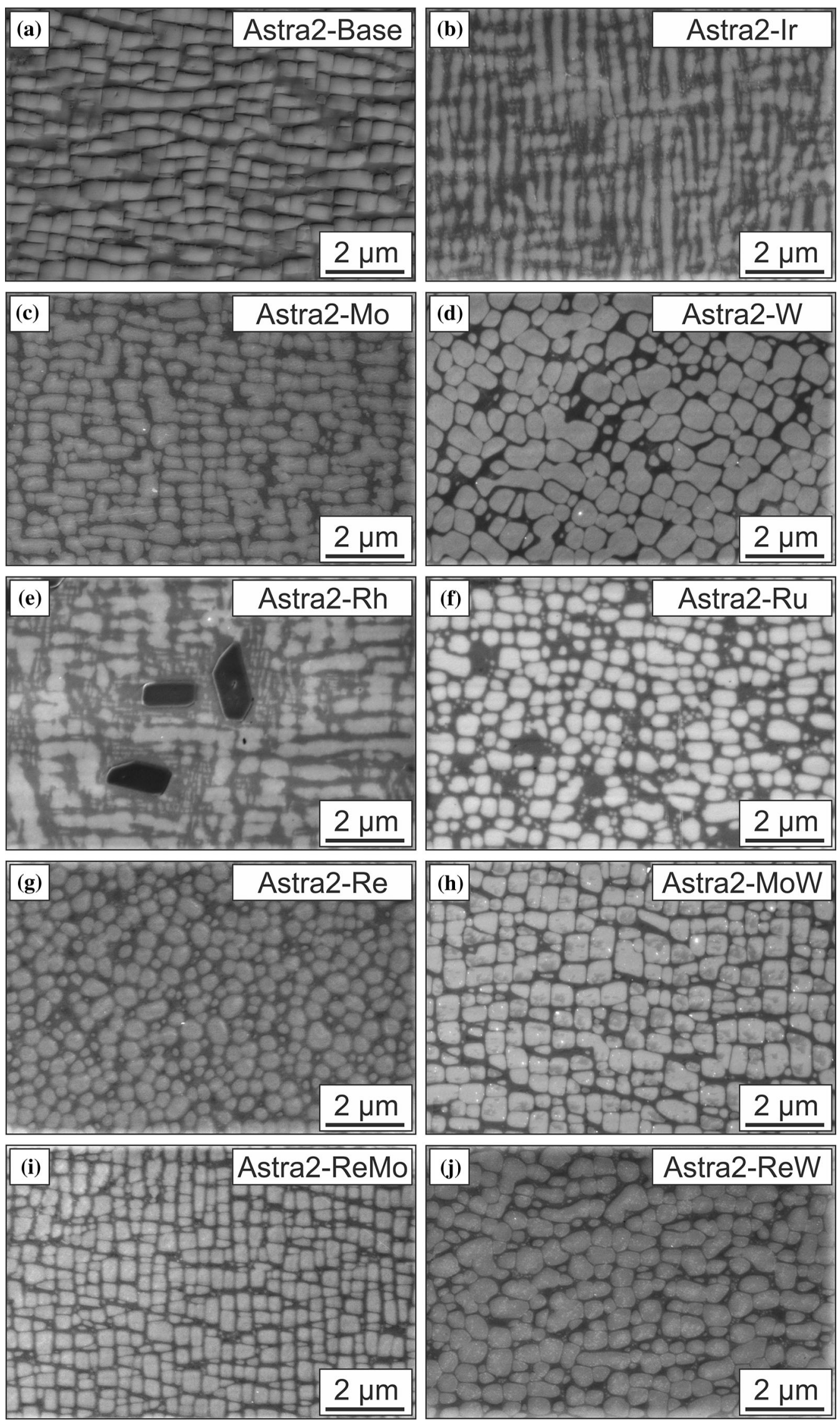

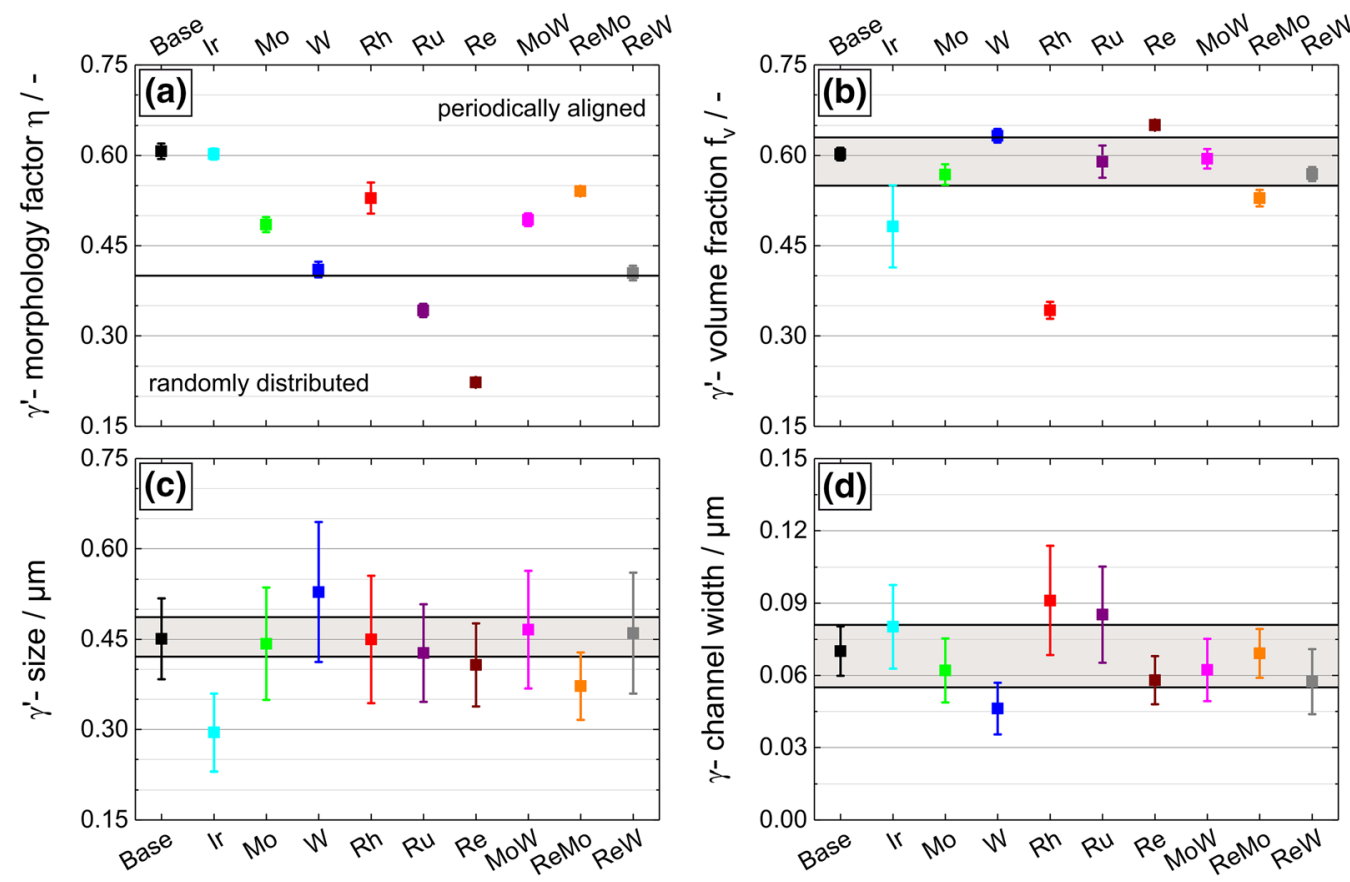

Fig. 3-(a) $\gamma^{\prime}$-Morphology factor, (b) $\gamma^{\prime}$-volume fraction, (c) mean equivalent cubic volume $\gamma^{\prime}$-edge length and (d) $\gamma$-channel width of the alloys in the full heat-treated condition; see Table II.

in the range of $68 \pm 13 \mathrm{~nm}$ as shown in Figure 3(d). Due to the high $\gamma^{\prime}$-volume fraction and $\gamma^{\prime}$-size, Astra2-W shows the narrowest $\gamma$-channel width of $46 \pm 10 \mathrm{~nm}$. The relatively broad matrix channels of Astra2-Rh and Astra2-Ru might be an effect of the low $\gamma^{\prime}$-volume fraction of Astra2-Rh and the not considered secondary $\gamma^{\prime}$-precipitates for Astra2-Ru.

\section{B. Partitioning Behavior}

The partitioning ratio of the alloying elements at creep temperature was determined by analyzing the chemical composition of the $\gamma$ - and $\gamma^{\prime}$-phases after long-term heat treatment of 1000 hours at $1373 \mathrm{~K}$ $\left(1100{ }^{\circ} \mathrm{C}\right)$ and subsequent water quenching; see Figure 4.

$\operatorname{Rh}\left(k_{i}^{\gamma^{\prime}} / \gamma=1.31\right)$ and $\operatorname{Ir}\left(k_{i}^{\gamma^{\prime} / \gamma}=1.15\right)$ partition slightly to the $\gamma^{\prime}$-phase. The preference of $\mathrm{Rh}$ to partition in the $\gamma^{\prime}$-phase is in accordance with investigations of Murakami et al. and Yokokawa et al. ${ }^{[26,27]}$ According to former studies, Ir is mainly associated with a preferred partitioning in the $\gamma$-phase or is distributed almost equally between both phases. ${ }^{[26-28]}$ In these studies, a partitioning coefficient for $\operatorname{Ir}>1$ could only be observed, if additional elements with a higher preference to the $\gamma$-phase were alloyed, ${ }^{[26]}$ which is not the case for Astra2-Ir. The enrichment in the $\gamma^{\prime}$-phase indicates that both elements, Ir and $\mathrm{Rh}$, cannot serve as effective solid solution strengtheners. In contrast, $\mathrm{Ru}$ segregates preferentially in the $\gamma$-phase $\left(k_{i}^{\gamma^{\prime} / \gamma}=0.53\right)$. This is in agreement with APT investigations of Liu et al. and Ding et al. as well as TEM-EDS measurements of Pyczak et al..$^{[37-39]}$ The partitioning behavior of Mo in the three Mo-containing alloys, Astra2-Mo, Astra2-MoW and Astra2-ReMo, is

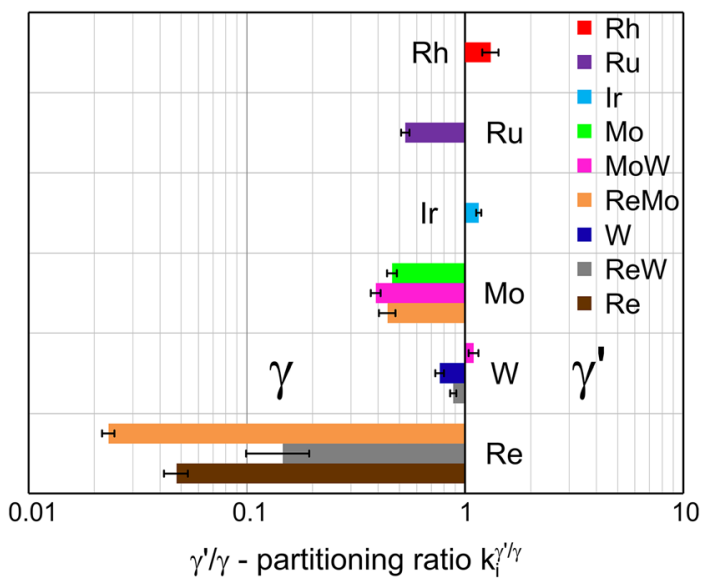

Fig. 4- $\gamma^{\prime} / \gamma$-Partitioning ratio of the selected alloying elements $\mathrm{Rh}$, $\mathrm{Ru}, \mathrm{Ir}, \mathrm{Mo}, \mathrm{W}$ and Re for all Astra2 alloys, which were analyzed by SEM-EDS measurements after long-term heat treatment at $1373 \mathrm{~K}$ $\left(1100{ }^{\circ} \mathrm{C}\right)$ for $1000 \mathrm{~h}$.

similar. The lowest partitioning coefficient of 0.39 was observed for Mo in Astra2-MoW. Since Mo has a stronger tendency to be enriched in the $\gamma$-phase compared to $\mathrm{W}$, see also, ${ }^{[26]} 2.6$ at. pct of Mo leads to a reverse partitioning behavior of $\mathrm{W}$ to the $\gamma^{\prime}$-phase in Astra2MoW. In the other alloys, Astra2-W and Astra2-ReW, W partitions slightly to the $\gamma$-phase. The varying partitioning behavior of $\mathrm{W}$ was also found by APT analysis. ${ }^{[18]}$ Amouyal et al. observed that W is preferentially enriched in the $\gamma^{\prime}$-phase of ternary Ni-Al-W alloys, whereas the partitioning behavior is reversed for multi-component alloys. Apparently, the small amount of just 1 at. pct Re is not sufficient to reject $\mathrm{W}$ out of the solid solution matrix, 

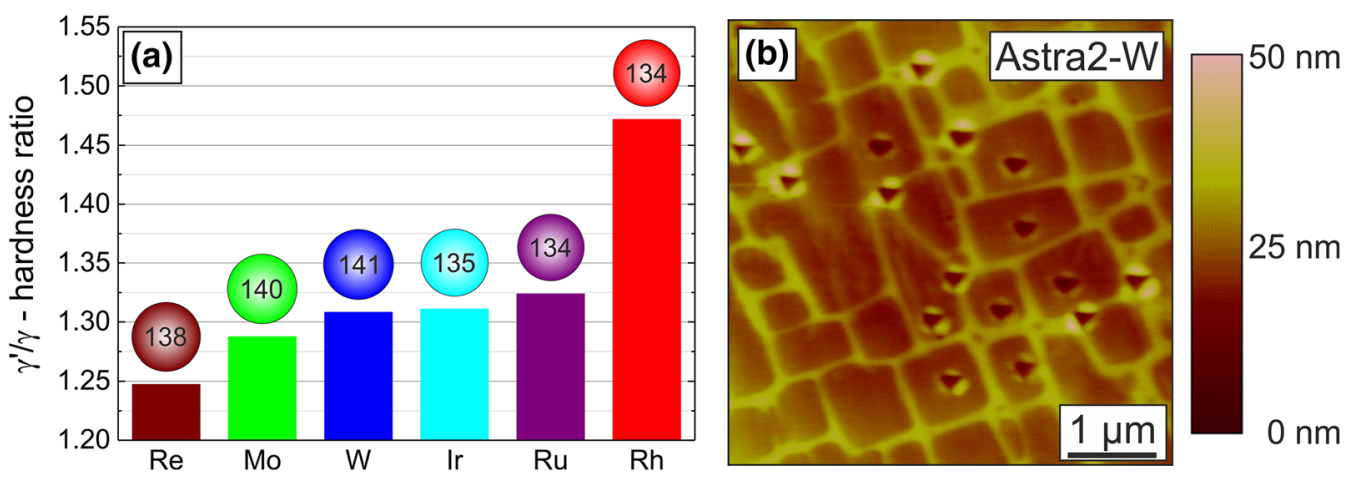

Fig. 5-(a) The $\gamma^{\prime} / \gamma$ hardness ratio for the alloys with Re, Mo, W, Ir, Ru and Rh and their Goldschmidt radii in pm and (b) an atomic force microscopy image of Astra2-W indicating the positions of the nanoindents.

although Re partitions even more strongly in the $\gamma$-phase than Mo. The strongest enrichment of an element in the $\gamma$-phase can be observed for Re with partitioning coefficients of $0.07 \pm 0.05$ in the Re-containing alloys. This is in line with former studies of Neumeier et al. and Heckl et al. ${ }^{[29,34]}$

\section{Hardness of $\gamma$-and $\gamma^{\prime}$-Phase}

Figure 5(a) shows the measured hardness ratio for the $\gamma^{\prime}$ - and $\gamma$-phase for the Astra2 alloys with one additional alloying element and its Goldschmidt radius in pm. ${ }^{[40]}$ Unfortunately, the $\gamma^{\prime} / \gamma$ hardness ratio of the Astra2Base alloy was not determined. The positioning of the nanoindents in the $\gamma$-matrix as well as in the $\gamma^{\prime}$-phase is shown as an example by an atomic force microscopy image of Astra2-W in Figure 5(b).

Since the hardness of the $\gamma^{\prime}$-phase is always higher than that of the $\gamma$-matrix, as well known from the literature, ${ }^{[41]}$ the $\gamma^{\prime} / \gamma$-hardness ratio is $>1$ for all alloys. The addition of Re leads to the strongest increase of the $\gamma$-matrix hardness and therefore to the lowest $\gamma^{\prime} / \gamma$-hardness ratio followed by Mo. Compared to previous studies on Re-containing alloys, ${ }^{[42-44]}$ the hardness ratio of Astra2-Re is slightly lower (1.25 compared to 1.30-1.43). However, the Re content in the present alloy is significantly higher than in the other alloys (3.6 at. pct compared to 1-2 at. pct); thus, the value is in excellent agreement with the literature. The hardness ratios of the $\mathrm{W}$-, Ir- and Ru-containing alloys are almost equal, while the Rh-containing alloy shows the highest $\gamma^{\prime} / \gamma$-hardness ratio. As shown in Figure 5(a), the Goldschmidt radii are clearly not the decisive factor, which influences the $\gamma^{\prime} / \gamma$-hardness ratio, as will be elaborated in more detail in Section IV.

\section{Creep Properties}

Figure 6(a) shows the compression creep curves for the Astra2 series at a testing temperature of $1373 \mathrm{~K}$ $\left(1100{ }^{\circ} \mathrm{C}\right)$ and a constant stress of $140 \mathrm{MPa}$.

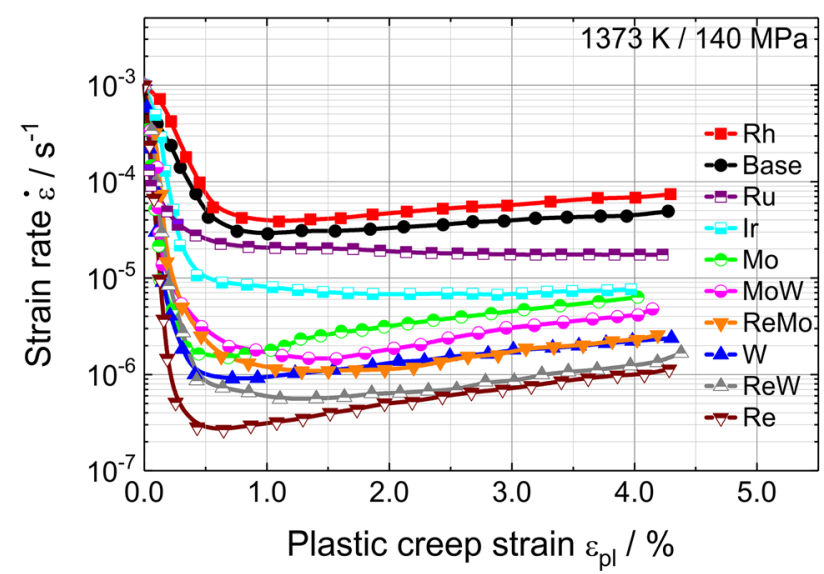

(a)

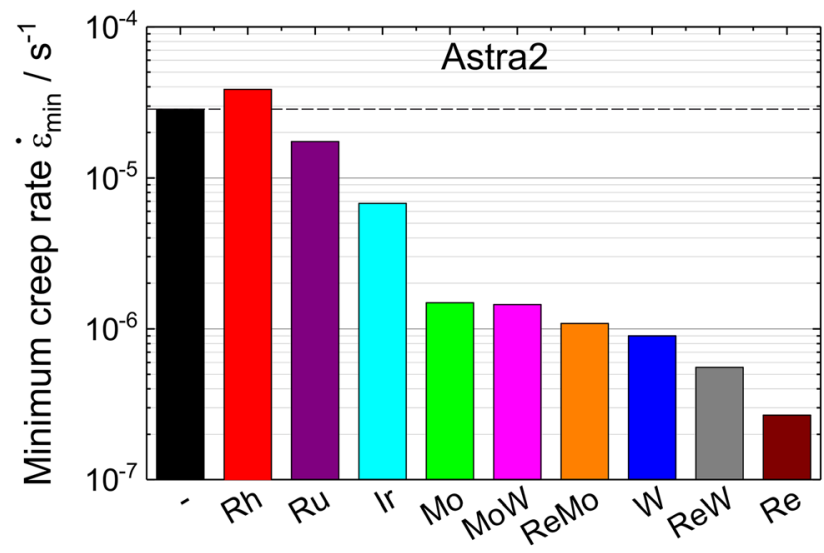

(b)

Fig. 6- (a) Compressive creep curves at $1373 \mathrm{~K}\left(1100{ }^{\circ} \mathrm{C}\right)$ and 140 $\mathrm{MPa}$ for the Astra2 series and (b) the corresponding minimum creep rates.

All alloys show an improved creep strength compared to the base alloy except Astra2-Rh. A slight decrease of the strain rates could be determined for the $\mathrm{Ru}-$ and Ir-containing alloys with an almost constant secondary creep regime until the end of the tests. Improvement of 
the creep properties of $\mathrm{Ni}$-base superalloys because of the addition of $\mathrm{Ru}$ was observed in combination with $\mathrm{Re}$ earlier by Neumeier et al. and Chen et al. ${ }^{[34,45]}$ Further improvement of the creep behavior was observed for the Mo-, W- and especially Re-containing alloys with the lowest creep minimum of $2.67 \times 10^{-7} \mathrm{~s}^{-1}$ (see Figure 6(b)). Despite the stronger enrichment of Mo in the $\gamma$-phase, the W-containing alloy Astra2-MoW and Astra2-W in particular show lower minimum creep rates compared to Astra2-Mo. The plastic strain, at which the creep minima occurred, differs between 0.6 and 1.5 pct.

\section{DISCUSSION}

\section{A. Correlation Between Partitioning Behavior and $\gamma^{\prime} / \gamma$ Hardness Ratio}

The partitioning behavior of the alloying elements in Ni-base superalloys is of major interest for their application in high-temperature environments. At elevated temperatures and low stresses, creep deformation mainly takes place in the $\gamma$-matrix and dislocations have to circumvent the $\gamma^{\prime}$-precipitates by glide and climb processes. ${ }^{[9,17]}$ Hence, the enrichment of alloying elements to strengthen the $\gamma$-matrix is of prime importance to improve the creep resistance. Measuring the hardness of the $\gamma / \gamma^{\prime}$-microstructure by nanoindentation in an AFM is a suitable method for correlating the partitioning behavior of alloying elements with the mechanical properties of each individual phase. ${ }^{[41,43]}$ Figure 7 reveals a clear correlation between the $\gamma^{\prime} / \gamma$-hardness ratio and the $\gamma^{\prime} / \gamma$-partitioning ratio for the Astra2 alloys, although the hardness was determined by nanoindentation at room temperature and the $\gamma^{\prime} / \gamma$-partitioning behavior reflects the condition at $1373 \mathrm{~K}$ $\left(1100{ }^{\circ} \mathrm{C}\right)$.

It can be observed that the more the alloying element partitions in the $\gamma$-phase, the lower the room temperature $\gamma^{\prime} / \gamma$-hardness ratio is. This is reasonable, since (1) the atomic radii of $\mathrm{Ir}, \mathrm{Ru}$ and $\mathrm{Re}$ are almost equal and those of Mo and W are only slightly larger and (2) the strengthening constants of Mo, Re, Ru and W for solid solution strengthening in pure $\mathrm{Ni}$ are all in a similar range of 977 to $1068 \mathrm{MPa} / \mathrm{at}^{0.5} \cdot{ }^{[46,47]}$ In contrast, the

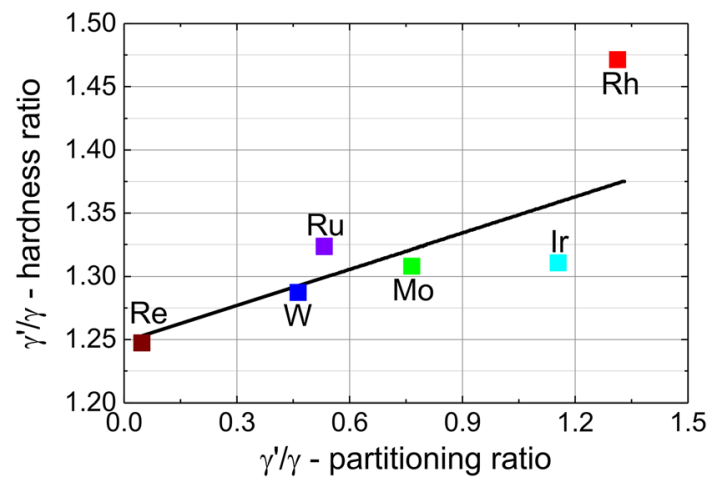

Fig. 7-The $\gamma^{\prime} / \gamma$-hardness ratio $v s$. the $\gamma^{\prime} / \gamma$-partitioning ratio of the Astra 2 alloys with one additional alloying element Re, Mo, Ru, W, Ir and $\mathrm{Rh}$. strengthening constant of $\mathrm{Rh}$ is comparably low, i.e., $520 \mathrm{MPa} / \mathrm{at}^{0.5},{ }^{[46]}$ which explains the deviation of the Rh-containing alloy compared to the other alloys despite the similar atomic radii. In summary, because of the similar solid solution strengthening constants, a lower partitioning ratio leads to a higher concentration of the alloying element in the $\gamma$ matrix and thus to a higher $\gamma$-matrix hardness and a lower $\gamma^{\prime} / \gamma$ hardness ratio at room temperature.

\section{B. Influence of $\gamma / \gamma^{\prime}$-Microstructure on the Creep Properties}

Many microstructural factors, such as the $\gamma^{\prime}$-volume fraction, $\gamma^{\prime}$-size and $\gamma$-channel width, contribute to the creep strength of Ni-base superalloys at elevated temperatures. ${ }^{[13,29,37,38,41]}$ The adjusted heat treatments lead to similar $\gamma^{\prime}$-size and also the $\gamma^{\prime}$-volume fractions differ only slightly between most of the investigated Astra2 alloys. Their minimum creep rate $\dot{\varepsilon}_{\min }$ is plotted as a function of the $\gamma^{\prime}$-volume fraction after the full heat treatment at $1143 \mathrm{~K}\left(870{ }^{\circ} \mathrm{C}\right)$ for 24 hours and after the long-term heat treatment at $1373 \mathrm{~K}\left(1100{ }^{\circ} \mathrm{C}\right)$ for 1000 hours in Figure 8.

The former condition corresponds to the initial condition at the beginning of the creep experiment while the latter represents the equilibrium $\gamma^{\prime}$-volume fraction at the creep temperature of $1373 \mathrm{~K}\left(1100{ }^{\circ} \mathrm{C}\right)$. During the creep experiments the alloys' $\gamma^{\prime}$-volume fraction declines continuously and ranges between both conditions.

Even though the Rh- and Ir-containing alloys with the lowest $\gamma^{\prime}$-volume fractions reveal relatively high minimum creep rates, a general tendency that a higher $\gamma^{\prime}$-volume fraction results in a lower minimum creep rate could only be partially proven. For example, the alloys Astra2-W and Astra2-ReMo have a similar creep strength, although their $\gamma^{\prime}$-volume fractions differ by about 10 pct. The fact that the $\gamma^{\prime}$-volume fraction is not the major influencing factor becomes even clearer when comparing the Astra2-Mo, -W and -Re, which all exhibit similar $\gamma^{\prime}$-volume fractions, but their minima creep rates differ by about one order of magnitude. Also

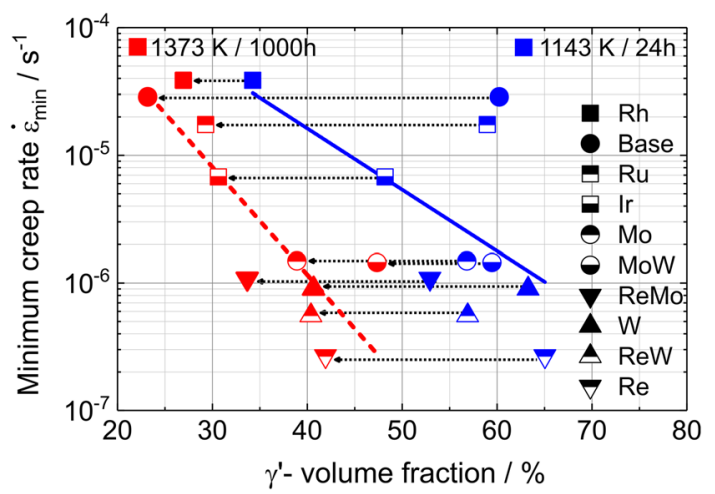

Fig. 8-Minimum creep rate $\dot{\varepsilon}_{\text {min }}$ as a function of the $\gamma^{\prime}$-volume fraction of the Astra2 series after the full heat treatment at $1143 \mathrm{~K}$ $\left(870{ }^{\circ} \mathrm{C}\right)$ for $24 \mathrm{~h}$ (blue symbols) and the long-term heat treatment at $1373 \mathrm{~K}\left(1100{ }^{\circ} \mathrm{C}\right)$ for $1000 \mathrm{~h}$ (red symbols) (Color figure online). 
the $\gamma^{\prime}$-morphology does not explain the differences in the creep strength of these three alloys, since the alloy Astra2-Re with the least beneficial $\gamma^{\prime}$-morphology reveals the highest creep strength. It is noticeable that the minimum creep rates of all Re-containing alloys, Astra2-ReMo, Astra2-ReW and especially Astra2-Re, are below the fitted lines in Figure 8, indicating that in addition to the influence of the $\gamma^{\prime}$-volume fraction another mechanism has a major effect on the creep strength.

\section{Influence of the Effective Diffusion Coefficient on the Creep Properties}

The rate-controlling mechanism during high-temperature creep is the diffusion of the alloying elements in the $\gamma$-matrix. The effective diffusivity $D_{\text {eff }}$ is used to describe the diffusion as a function of the elemental composition of the $\gamma$-matrix in multi-component alloys. In this study, the approach of Zhu et al. was chosen for calculating $D_{\text {eff, }}{ }^{[9]}$ which was shown to be a useful parameter to estimate the effective diffusivity of a solid solution, although further studies are needed to find advanced physically based models. ${ }^{[10]} D_{\text {eff }}$ is calculated by using $D_{\text {eff }}^{0}$ and $Q^{\text {eff }}$ representing the harmonic mean of the atomic concentration $x_{\mathrm{m}}$ and the pre-exponential factor of solute $m$ in nickel $D_{0}^{m, \mathrm{Ni}}$ and the weighted average of contributions from the different metal solutes $m$ on activation energy $Q^{\text {eff }}{ }^{[9]}$

$$
\begin{gathered}
D^{\mathrm{eff}}=D_{0}^{\mathrm{eff}} \exp \left(\frac{-Q^{\mathrm{eff}}}{R T}\right), \\
D^{\mathrm{eff}}=\frac{1}{\sum_{m} \frac{x_{m}}{D_{0}^{m, \mathrm{Ni}}}}, \\
Q^{\mathrm{eff}}=Q^{\mathrm{Ni}}+\sum_{m} x_{m} Q^{m, \mathrm{Ni}} .
\end{gathered}
$$

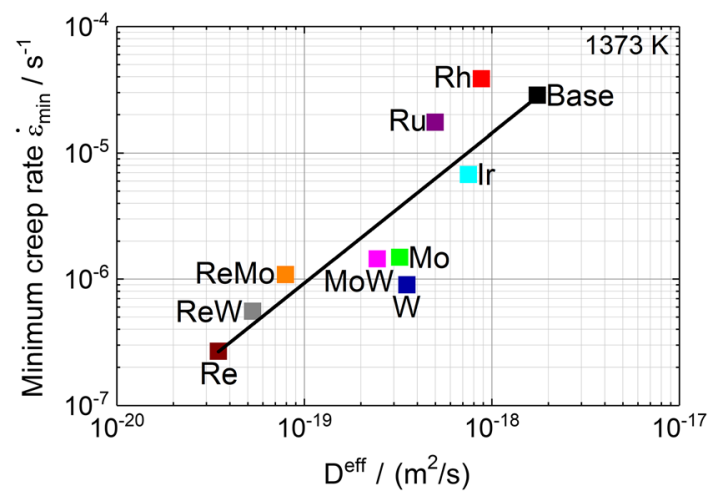

Fig. 9-Minimum creep rate as a function of the effective diffusion coefficient at $1373 \mathrm{~K}\left(1100{ }^{\circ} \mathrm{C}\right)$ of the Astra2 series.
The calculation of the activation energies as well as the pre-exponential factors for all elements at the testing temperature of $1373 \mathrm{~K}\left(1100{ }^{\circ} \mathrm{C}\right)$ was done based on literature data from Reference [21, 48-51].

Figure 9 shows the correlation of the minimum creep rate $\dot{\varepsilon}_{\min }$ as a function of the effective diffusion coefficient $D_{\text {eff }}$ for the studied Astra2 series.

It can be seen that the effective diffusion coefficient correlates well with the experimentally determined minimum creep rates. By reducing the effective diffusion coefficient of an alloy the creep strength increases. This explains why Astra2-Re shows a much lower creep rate than Astra2-Mo, although both have similar $\gamma^{\prime}$-volume fractions. In accordance with investigations of the Astra1 series from Heckl et al. ${ }^{\left[{ }^{[2]}\right.}$ the Astra2-Re alloy with the highest amount of Re leads to a significant solid solution strengthening of the $\gamma$-matrix, resulting in the highest creep strength. Although W partitions less to the $\gamma$-phase than Mo, Astra2-ReW exhibits a lower effective diffusion coefficient as well as an improved creep resistance in contrast to Astra2-ReMo because of the lower diffusivity of $\mathrm{W}$ in Ni compared to Mo ${ }^{[49,50]}$ The unexpected high creep strength of the Astra-W alloy may be influenced by microstructural parameters like the relatively high $\gamma^{\prime}$-volume fraction and the corresponding narrow $\gamma$-channel width. The deviation from the trend line towards higher creep rates of Astra2-Ru can be attributed to the more spherical morphology and the unordered arrangement of the $\gamma^{\prime}$-phase and the broad $\gamma$-channel leading to an easier climb of the dislocations to overcome the $\gamma^{\prime}$-precipitate phase. As mentioned before, the low creep strength of the Astra2- $\mathrm{Rh}$ can be correlated with the depletion of $\mathrm{Rh}$ in the $\gamma$-matrix because of the stronger partitioning in the $\gamma^{\prime}$-phase and the formation of the $\beta$-(Ni,Rh)Al phase. Despite having one of the lowest interdiffusion coefficients of the $4 \mathrm{~d}$ platinum group metals in pure nickel, ${ }^{[21]}$ the lower amount of $\mathrm{Rh}$ in the $\gamma$-matrix cannot significantly reduce $D_{\text {eff }}$ in the Astra2-Rh alloy.

In general, the results show that microstructural effects such as the morphology, size and volume fraction of the $\gamma^{\prime}$-precipitates have to be taken into account. However, the creep strength of the Astra2 series at high temperatures significantly depends on the diffusivity and concentration of the alloying elements in the $\gamma$-solid solution. This means that the impact of alloying elements on the creep strength at high temperatures is the strongest for elements that (1) partition predominantly to the $\gamma$-phase and (2) have a relatively low interdiffusion coefficient in Ni. Consequently, the calculation of the partitioning behavior and the resulting interdiffusion coefficient is an useful parameter for the evaluation of the high-temperature creep strength of single crystalline Ni-base superalloys in optimization tools for alloy development. ${ }^{[52]}$

\section{CONCLUSION}

Nine derivatives of the Astra2-Base alloy containing different solid solution strengtheners ( $\mathrm{Ir}, \mathrm{Mo}, \mathrm{Re}, \mathrm{Rh}$, $\mathrm{Ru}, \mathrm{Re}, \mathrm{W})$ were investigated to understand the 
influence of solid solution strengthening elements on the high-temperature creep strength of Ni-base superalloys at $1373 \mathrm{~K}\left(1100{ }^{\circ} \mathrm{C}\right)$. Special emphasis was placed on the partitioning behavior and interdiffusion coefficient of the alloying elements. The most important findings are summarized as follows:

- All alloys of the Astra2 series exhibit a two-phase $\gamma /$ $\gamma^{\prime}$-microstructure except for the Rh-containing one, which forms detrimental $\beta$-(Ni,Rh)Al phases.

- A more precise conversion between the measured area fraction of a binarized micrograph to the actual $\gamma^{\prime}$-volume fraction was derived for ordered $\gamma / \gamma^{\prime}$-microstructures with non-perfectly cuboidal precipitates.

- The $\gamma^{\prime}$-volume fraction does not play the most important role regarding the creep properties at $1373 \mathrm{~K}\left(1100{ }^{\circ} \mathrm{C}\right)$. Astra2-ReMo and Astra2-W reveal approximately equal creep minima despite a difference of almost 10 pct of the $\gamma^{\prime}$-volume fraction. Astra2-Mo, -W and -Re exhibit similar $\gamma^{\prime}$ volume fractions, but their minima creep rates differ by about one order of magnitude.

- The key factor for the creep strength in the high temperature/low stress regime is the effective diffusion coefficient. This means a stronger partitioning to the $\gamma$-matrix of slowly diffusing elements is beneficial for increasing the creep resistance. The Re-containing alloys showed the best creep properties because of the lowest effective diffusion coefficients followed by $\mathrm{W}$ - and Mo-containing alloys.

- $\mathrm{Re}$ is the most effective solid solution strengthening element in the high-temperature creep regime followed by $\mathrm{W}, \mathrm{Mo}$, Ir and $\mathrm{Ru}$, while $\mathrm{Rh}$ results in the worst creep strength.
SFB/TR 103: "From Atoms to Turbine Blades-A Scientific Approach for Developing the Next Generation of Single Crystal Superalloys."

\section{OPEN ACCESS}

This article is licensed under a Creative Commons Attribution 4.0 International License, which permits use, sharing, adaptation, distribution and reproduction in any medium or format, as long as you give appropriate credit to the original author(s) and the source, provide a link to the Creative Commons licence, and indicate if changes were made. The images or other third party material in this article are included in the article's Creative Commons licence, unless indicated otherwise in a credit line to the material. If material is not included in the article's Creative Commons licence and your intended use is not permitted by statutory regulation or exceeds the permitted use, you will need to obtain permission directly from the copyright holder. To view a copy of this licence, visit http://creat ivecommons.org/licenses/by/4.0/.

\section{FUNDING}

Open Access funding enabled and organized by Projekt DEAL.

\section{APPENDIX A}

In the following, we propose an approach to derive the $\gamma^{\prime}$-volume fraction, the equivalent cubic and spherical $\gamma^{\prime}$-precipitate radii as well as the $\gamma$-channel width from a binarized micrograph of periodically aligned precipitates using the morphology factor $\eta$.

\section{ACKNOWLEDGMENTS}

The authors acknowledge funding by the Deutsche Forschungsgemeinschaft (DFG) through project A6, B1 and Z01 of the Collaborative Research Center

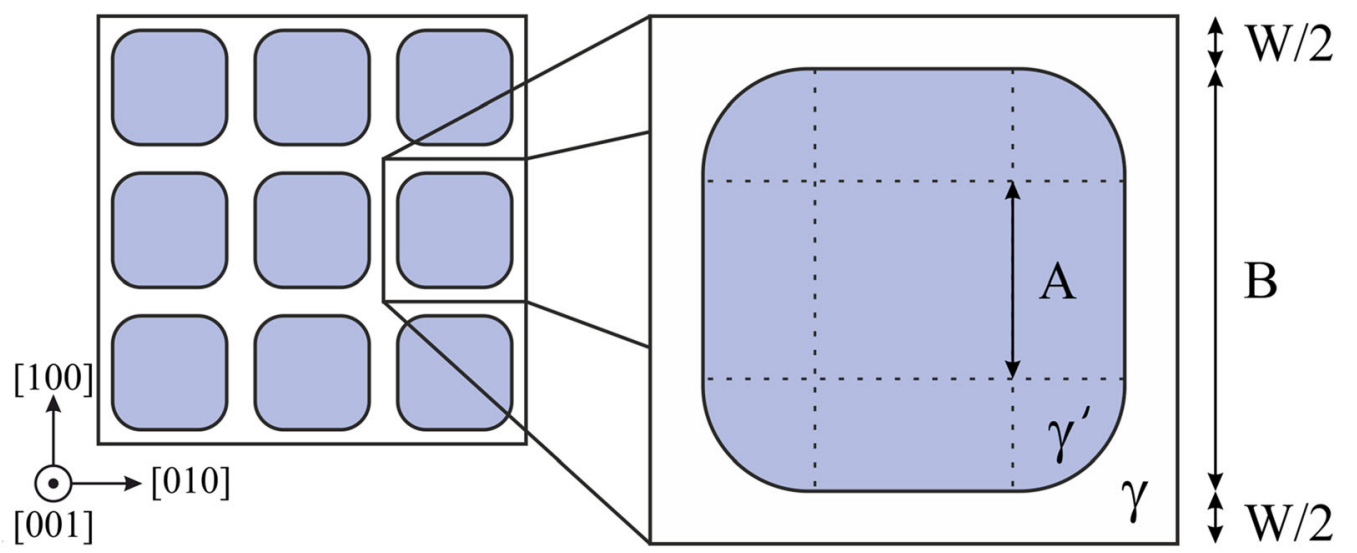

Fig. A1-Periodically aligned $\gamma^{\prime}$-precipitates with a morphology factor $\eta$ of 0.6 viewed on the (001) plane. A single unit cell can be characterized by the $\gamma^{\prime}$-length parameters $A$ and $B$ as well as the $\gamma$-channel width $W$. Modified approach based on the work of Bürgel et al.$^{[7]}$ 


\section{DETERMINATION OF THE $\Gamma^{\prime}$-VOLUME FRACTION}

For Ni-base superalloys with a high volume fraction of coherent and periodically aligned $\gamma^{\prime}$-precipitates, the measured $\gamma^{\prime}$-area fraction does not equal the actual $\gamma^{\prime}$-volume fraction. Thus, Bürgel et al. ${ }^{[7]}$ introduced an approach to calculate the volume fraction based on geometrical considerations and the following assumptions:

- The $\gamma^{\prime}$-precipitates are perfectly cuboidal.

- The $\gamma^{\prime}$-precipitates are periodically aligned and equal in size resulting in a constant $\gamma$-channel width.

In the following, the approach is extended to non-perfectly cuboidal $\gamma^{\prime}$-precipitates with variable morphology factors. The idealized microstructure and the relevant length parameters are shown schematically in Figure A1.

The $\gamma^{\prime}$-area fraction $f_{\mathrm{A}}$ of one unit cell (see Figure A1) and thus also of the entire $\gamma / \gamma^{\prime}$-composite, is given by:

$$
f_{\mathrm{A}}=\frac{A^{2}+4 A \frac{B-A}{2}+\pi\left(\frac{B-A}{2}\right)^{2}}{(B+W)^{2}} .
$$

Substituting $A$ in Eq. (A1) with $B \eta$ yields:

$$
f_{\mathrm{A}}=\frac{(B \eta)^{2}+4 B^{2} \eta \frac{1-\eta}{2}+\pi B^{2}\left(\frac{1-\eta}{2}\right)^{2}}{(B+W)^{2}} .
$$

Similar to Bürgel et al., the ratio of $B$ and $W$, which is termed $Q$, is substituted into Eq. (A2):

$$
f_{\mathrm{A}}=\frac{2 \eta Q^{2}-\eta^{2} Q+Q^{2}\left(\frac{\pi}{4}-\frac{\eta \pi}{2}+\frac{\eta^{2} \pi}{4}\right)}{Q^{2}+2 Q+1}
$$

Solving Eq. (A3) for $Q$ yields:

$$
Q_{1 / 2}=\frac{f_{A} \mp \sqrt{f_{A}\left(2 \eta-\eta^{2}+\frac{\pi}{4}-\frac{\eta \pi}{2}+\frac{\eta^{2} \pi}{4}\right)}}{-f_{A}+2 \eta-\eta^{2}+\frac{\pi}{4}-\frac{\eta \pi}{2}+\frac{\eta^{2} \pi}{4}}
$$

Hereby, only the positive sign is applicable, since otherwise $Q$ would become negative. The $\gamma^{\prime}$-volume fraction $f_{\mathrm{V}}$ is given by:

$$
f_{\mathrm{V}}=\frac{A^{3}+6 \frac{B-A}{2} A^{2}+3 \pi A\left(\frac{B-A}{2}\right)^{2}+\frac{4}{3} \pi\left(\frac{B-A}{2}\right)^{3}}{(B+W)^{3}}
$$

Substituting $A$ in Eq. (A5) with $B \eta$ yields:

$$
f_{\mathrm{V}}=\frac{B^{3}\left(3 \eta^{2}-2 \eta^{3}+\frac{3 \pi}{4} \eta(1-\eta)^{2}+\frac{\pi}{6}(1-\eta)^{3}\right)}{(B+W)^{3}}
$$

Again, $Q$ can be used to eliminate $B$ and $W$ in Eq. (A6):

$$
f_{\mathrm{V}}=\frac{Q^{3}\left(3 \eta^{2}-2 \eta^{3}+\frac{3 \pi}{4} \eta(1-\eta)^{2}+\frac{\pi}{6}(1-\eta)^{3}\right)}{Q^{3}+3 Q^{2}+3 Q+1}
$$

Thus, the $\gamma^{\prime}$-volume fraction can be calculated by the measured area fraction $f_{\mathrm{A}}$ and the morphology factor $\eta$.

\section{DETERMINATION OF THE VOLUME EQUIVALENT PRECIPITATE RADII AND CHANNEL WIDTH}

The equivalent cubic $r_{\text {cub }}$ and spherical $r_{\text {sph }}$ radii of the $\gamma^{\prime}$-precipitates in a binarized SEM micrograph can be calculated by the area fraction $A_{\mathrm{P}}$ and the morphology factor $\eta$ of each individual precipitate and by assuming equiaxed $\gamma^{\prime}$-precipitates. The absolute measured area of a precipitate $A_{\mathrm{P}}$ is given as follows:

$$
A_{\mathrm{P}}=A^{2}+4 A \frac{B-A}{2}+\pi\left(\frac{B-A}{2}\right)^{2}
$$

Substituting $A$ in Eq. (A8) with $B \eta$ and solving for $B$ yields:

$$
B=\sqrt{\frac{A_{\mathrm{P}}}{\left(\eta^{2}\left(\frac{\pi}{4}-1\right)+\eta\left(2-\frac{\pi}{2}\right)+\frac{\pi}{4}\right)}}
$$

Furthermore, the absolute volume $V_{\mathrm{P}}$ of an equiaxed $\gamma^{\prime}$-precipitate is given as follows:

$$
V_{\mathrm{P}}=B^{3}\left(3 \eta^{2}-2 \eta^{3}+\frac{3 \pi}{4} \eta(1-\eta)^{2}+\frac{\pi}{6}(1-\eta)^{3}\right)
$$

The equivalent cubic $r_{\text {cub }}$ and spherical $r_{\text {sph }}$ radii of a $\gamma^{\prime}$-precipitate follow straightforwardly:

$$
\begin{gathered}
r_{\mathrm{cub}}=\sqrt[3]{\frac{V_{\mathrm{p}}}{8}} \\
r_{\mathrm{sph}}=\sqrt[3]{\frac{3 V_{\mathrm{p}}}{4 \pi}}
\end{gathered}
$$

Additionally, the mean $\gamma$-channel width $W$ is simply given by the ratio of $B$ and $Q$.

\section{REFERENCES}

1. P. Caron and T. Khan: Mater. Sci. Eng., 1983, vol. 61, pp. 173-84.

2. R.C. Reed: The Superalloys: Fundamentals and Applications, 1st ed., Cambridge University Press, New York, 2006.

3. M.V. Nathal: Metall. Trans. A, 1987, vol. 18A, pp. 1961-70.

4. T. Murakumo, T. Kobayashi, Y. Koizumi, and H. Harada: Acta Mater., 2004, vol. 52, pp. 3737-44.

5. T.M. Pollock and A.S. Argon: Acta Metall. Mater., 1992, vol. 40, pp. $1-30$. 
6. J.Y. Buffiere and M. Ignat: Acta Metall. Mater., 1995, vol. 43, pp. 1791-97.

7. R. Bürgel, H.J. Maier, and T. Niendorf: Handbuch Hochtemperatur-Werkstofftechnik: Grundlagen, Werkstoffbeanspruchungen, Hochtemperaturlegierungen und-beschichtungen; mit 66 Tabellen, 4, überarbst ed., Vieweg + Teubner, Wiesbaden, 2011.

8. R. Sowa, S. Arabasz, and M. Parlinska-Wojtan: Zastita Mater., 2016, vol. 57, pp. 274-81.

9. Z. Zhu, H. Basoalto, N. Warnken, and R.C. Reed: Acta Mater., 2012, vol. 60, pp. 4888-4900.

10. M. Pröbstle, S. Neumeier, P. Feldner, R. Rettig, H.E. Helmer, R.F. Singer, and M. Göken: Mater. Sci. Eng. A, 2016, vol. 676, pp. 411-20.

11. P. Pandey, A.K. Sawant, B. Nithin, Z. Peng, S.K. Makineni, B. Gault, and K. Chattopadhyay: Acta Mater., 2019, vol. 168, pp. 37-51.

12. K. Harris, G.L. Erickson, S.L. Sikkenga, W.D. Brentnall, J.M. Aurrecoechea, and K.G. Kubarych: in Superalloys 1992 (Seventh International Symposium), TMS, 1992, pp. 297-306.

13. A.F. Giamei and D.L. Anton: Metall. Trans. A, 1985, vol. 16A, pp. 1997-2005.

14. C.L. Fu, R. Reed, A. Janotti, and M. Kremar: in Superalloys 2004 (Tenth International Symposium), TMS, 2004, pp. 867-76.

15. X. Wu, S.K. Makineni, C.H. Liebscher, G. Dehm, J. Rezaei Mianroodi, P. Shanthraj, B. Svendsen, D. Bürger, G. Eggeler, D. Raabe, and B. Gault: Nat. Commun., 2020, vol. 11, p. 389.

16. R. Rettig, K. Matuszewski, A. Müller, H.E. Helmer, N.C. Ritter, and R.F. Singer: in Superalloys 2016, M. Hardy, E. Huron, U. Glatzel, B. Griffin, B. Lewis, C. Rae, V. Seetharaman, and S. Tin, eds., John Wiley \& Sons, Inc., Hoboken, NJ, 2016, pp. 35-44.

17. E. Fleischmann, M.K. Miller, E. Affeldt, and U. Glatzel: Acta Mater., 2015, vol. 87, pp. 350-56.

18. Y. Amouyal, Z. Mao, and D.N. Seidman: Acta Mater., 2010, vol. 58 , pp. $5898-5911$.

19. O. Ajaja, T.E. Howson, S. Purushothaman, and J.K. Tien: Mater. Sci. Eng., 1980, vol. 44, pp. 165-72.

20. P. Wollgramm, H. Buck, K. Neuking, A.B. Parsa, S. Schuwalow, J. Rogal, R. Drautz, and G. Eggeler: Mater. Sci. Eng. A, 2015, vol. 628 , pp. $382-95$.

21. M.S.A. Karunaratne and R.C. Reed: Acta Mater., 2003, vol. 51, pp. 2905-19.

22. J. Chen, J. Xiao, L. Zhang, and Y. Du: J. Alloys Compd., 2016, vol. 657 , pp. $457-63$.

23. X. Tan, J. Liu, T. Jin, Z. Hu, H.U. Hong, B.G. Choi, I.S. Kim, Y.S. Yoo, and C.Y. Jo: Metall. Mater. Trans. A, 2012, vol. 43A, pp. 3608-14.

24. S. Gao, Y. Zhou, C.-F. Li, Z.-Q. Liu, and T. Jin: J. Alloys Compd., 2016, vol. 671, pp. 458-64.

25. A. Heckl, S. Neumeier, S. Cenanovic, M. Göken, and R.F. Singer: Acta Mater., 2011, vol. 59, pp. 6563-73.

26. H. Murakami, T. Honma, Y. Koizumi, and H. Harada: in Superalloys 2000 (Ninth International Symposium), TMS, 2000, pp. $747-56$.

27. T. Yokokawa, M. Osawa, K. Nishida, T. Kobayashi, Y. Koizumi, and H. Harada: Scripta Mater., 2003, vol. 49, pp. 1041-46.

28. J.S. Van Sluytman, A.L. Fontaine, J.M. Cairney, and T.M. Pollock: Acta Mater., 2010, vol. 58, pp. 1952-62.
29. A. Heckl, S. Neumeier, M. Göken, and R.F. Singer: Mater. Sci. Eng. A, 2011, vol. 528, pp. 3435-44.

30. A. Heckl, R. Rettig, S. Cenanovic, M. Göken, and R.F. Singer: $J$. Cryst. Growth, 2010, vol. 312, pp. 2137-44.

31. C.A. Schneider, W.S. Rasband, and K.W. Eliceiri: Nat. Methods, 2012, vol. 9, pp. 671-75.

32. J.P. MacSleyne, J.P. Simmons, and M. De Graef: Acta Mater., 2008, vol. 56, pp. 427-37.

33. J.S. Van Sluytman and T.M. Pollock: Acta Mater., 2012, vol. 60, pp. 1771-83.

34. S. Neumeier, F. Pyczak, and M. Göken: in Superalloys 2008 (Eleventh International Symposium), TMS, 2008, pp. 109-19.

35. W.C. Oliver and G.M. Pharr: J. Mater. Res., 1992, vol. 7, pp. 1564-83.

36. B. Przepiórzyński, S. Mi, B. Grushko, and M. Surowiec: Intermetallics, 2007, vol. 15, pp. 918-28.

37. F. Pyczak, S. Neumeier, and M. Göken: Mater. Sci. Eng. A, 2010, vol. 527 , pp. $7939-43$

38. S.H. Liu, C.P. Liu, W.Q. Liu, X.N. Zhang, P. Yan, and C.Y. Wang: Philos. Mag., 2016, vol. 96, pp. 2204-18.

39. Q. Ding, Z. Lao, H. Wei, J. Li, H. Bei, and Z. Zhang: Intermetallics, 2020, vol. 121, p. 106772.

40. C.J. Smithells: Metals Reference Book, Elsevier Science, Kent, 2014.

41. M. Göken and M. Kempf: Acta Mater., 1999, vol. 47, pp. 1043-52.

42. K. Durst and M. Göken: Mater. Sci. Eng. A, 2004, vols. 387-389, pp. $312-16$.

43. H. ur Rehman, K. Durst, S. Neumeier, A.B. Parsa, A. Kostka, G. Eggeler, and M. Göken: Mater. Sci. Eng. A, 2015, vol. 634, pp. 202-08.

44. S. Neumeier, F. Pyczak, and M. Göken: Philos. Mag., 2011, vol. 91, pp. 4187-99.

45. J. Chen, Q. Feng, L. Cao, and Z. Sun: Prog. Nat. Sci. Mater. Int., 2010, vol. 20, pp. 61-69.

46. H.A. Roth, C.L. Davis, and R.C. Thomson: Metall. Mater. Trans. A, 1997, vol. 28A, pp. 1329-35.

47. F. Diologent and P. Caron: Mater. Sci. Eng. A, 2004, vol. 385, pp. $245-57$.

48. S.B. Jung, T. Yamane, Y. Minamino, K. Hirao, H. Araki, and S. Saji: J. Mater. Sci. Lett., 1992, vol. 11, pp. 1333-37.

49. M.S.A. Karunaratne, P. Carter, and R.C. Reed: Mater. Sci. Eng. A, 2000, vol. 281, pp. 229-33.

50. M.S.A. Karunaratne and R.C. Reed: Defect. Diffus. Forum, 2005, vols. 237-240, pp. 420-25.

51. K. Monma, H. Suto, and H.J. Oikawa: Jpn. Inst. Met., 1964, vol. 28 , pp. $188-92$.

52. M. Markl, A. Müller, N. Ritter, M. Hofmeister, D. Naujoks, H. Schaar, K. Abrahams, J. Frenzel, A.P.A. Subramanyam, A. Ludwig, J. Pfetzing-Micklich, T. Hammerschmidt, R. Drautz, I. Steinbach, R. Rettig, R.F. Singer, and C. Körner: Metall. Mater. Trans. A, 2018, vol. 49A, pp. 4134-45.

Publisher's Note Springer Nature remains neutral with regard to jurisdictional claims in published maps and institutional affiliations. 